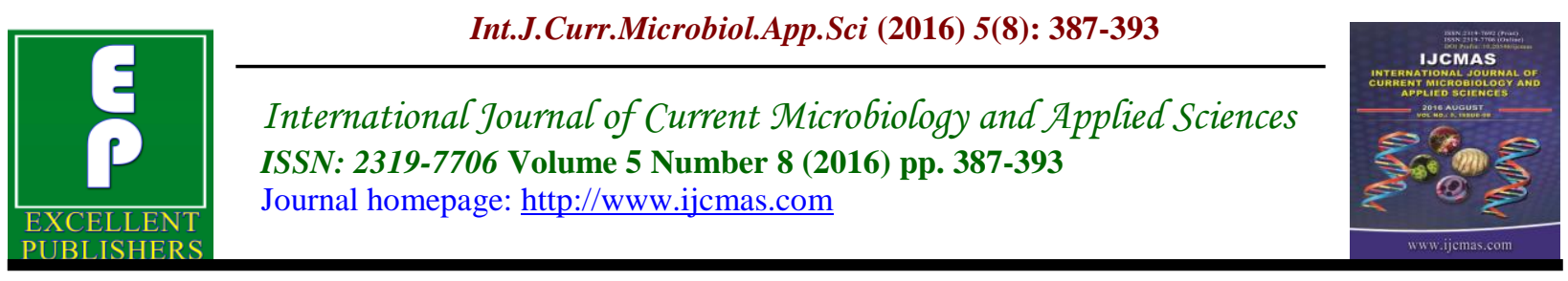

Original Research Article

http://dx.doi.org/10.20546/ijcmas.2016.508.041

\title{
Bacterial Aetiology and their Antibiotic Susceptibility Pattern of Otitis Media in Paediatric Age Group
}

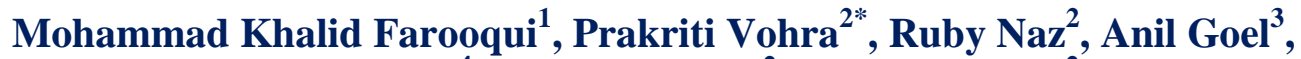 \\ Akil Hussain ${ }^{4}$, Sameena Khan ${ }^{2}$ and A.K. Malik ${ }^{2}$ \\ ${ }^{1}$ Department of ENT, SHKM, GMC, Mewat, India \\ ${ }^{2}$ Department of Microbiology, SHKM, GMC, Mewat, India \\ ${ }^{3}$ Department of Paediatrics, SHKM, GMC, Mewat, India \\ ${ }^{4}$ NIMS, Medical College, Jaipur, India \\ *Corresponding author
}

\begin{abstract}
A B S T R A C T
Keywords

Antibiotic

susceptibility,

Bacterial aetiology,

Otitis media,

Paediatric age.

\section{Article Info}

Accepted:

17 July 2016

Available Online:

10 August 2016

Otitis media is the most common reason for children to visit a medical practitioner and it is an important cause of preventable hearing loss. 564 patients of paediatric age group with symptoms of otitis media were studied from ENT and paediatrics department in microbiology department at SHKM, GMC, Mewat from June 2015 to May 2016. Isolates were identified by conventional methods and the antibiotic susceptibility profiles were determined by the standard disk diffusion method. Most common bacterial isolates included Pseudomonas aeruginosa (41.76\%), Staphylococcus aureus (33.3\%). The Gram positive bacteria antibiogram revealed high sensitivity to ciprofloxacin, cefoxitin, amoxyclav, gentamycin, teicoplanin and vancomycin. While Gram negative bacteria antibiogram reveals sensitivity to ciprofloxacin, ceftazidime, netilmycin, piperacillin tazobactam and gentamycin. Low levels of resistance were found among most clinical isolates in general to the commonly used antibiotics however, an increased frequency of MRSA was detected.
\end{abstract}

\section{Introduction}

Otitis media is an inflammatory disease of the mucosal lining of the middle ear, which includes a variety of medical conditions with different signs and symptoms.

Otitis media is most commonly caused by the build up of fluid behind the ear drum, as a result of a blockage to the Eustachian tube. Otitis media is more common in children, as their Eustachian tube is shorter and more horizontal than adults and is made up of more flaccid cartilage, which can impair its opening (Biradar, 2015). Infection can spread from the middle ear to involve the mastoid, facial nerve, labyrinth, lateral sinus, meninges and brain leading to mastoid abscesses, facial nerve paralysis, deafness, lateral sinus thrombosis, meningitis and intracranial abscesses (Abdel raouf et al., 2014).

The risk of prevalence of the diseases become higher in people with low 
socioeconomic status, Poor living conditions, overcrowding, substandard hygiene, and malnutrition and under resource health care (Farooqui et al., 2016).

It is the commonest childhood infectious disease worldwide starting early in life but in our environment; presentation may be in adult life it can be managed at the primary health care level thereby preventing the development of deafness and even fatal complications. Otitis media is more common in children, as their Eustachian tube is shorter and more horizontal than adults and is made up of more flaccid cartilage, which can impair its opening (Kumar et al., 2012).

The common causes of infection are nasopharyngeal disease and in children this usually means adenoids. These causes may be in the nose or sinuses or in the oropharynx and tonsils. Bacterial infections of the middle ear normally originate from the upper respiratory tract, with the bacteria entering the ear through the auditory (Eustachian) tube, the principal portal of entry to the ear (Basak et al., 2014).

Common aerobic bacteria causes otitis media are Staphylococcus aureus Pseudomonas aeruginosa, Escherichia coli, Streptococcus pyogenes, Proteus mirabilis, Klebsiella species, Haemophilus influenzae, Streptococcus pneumonia.

The present study was aimed at gaining knowledge about the type of pathogens responsible for infection in this region and their resistance patterns which will help the clinicians to choose the right empirical treatment. Antibiotic resistance pattern are varied according to geographical region, and very few studies are published about this especially from Haryana.

\section{Material and Methods}

To study bacterial etiologic agents and their antibiotic susceptibility patterns of otitis media in paediatric age group in collaboration of Paediatrics and ENT department of SHKM GMC Nalhar, Mewat.

Ethical concern: Permission from institutional ethical committee was taken for conducting this study.

Sample size calculation: sample size is calculated from prevalence $(6 \%)$ of otitis media in children (Rupa et al., 1999) with help of formula $\mathrm{PQ} / \mathrm{r}^{2}$

$\mathrm{P}$; prevalence, $\mathrm{Q}=1-\mathrm{P}, \mathrm{r}=.02$

We studied 564 patients of one to 14 years age group (Paediatric) who were attend OPD with symptoms of otitis media. They were enrolled for study and written consent had been taken. Patient of otitis media presented with complain of purulent or muco-purulent ear discharge with or without fever and otalgia (Park, 2002).

\section{Study duration}

Duration of study was from June 2015 to May 2016, on the basis of following inclusion and exclusion criteria. Detailed clinical history regarding unique identification number, name, age and sex, duration of discharge, other associated symptoms and antibiotic therapy were noted down.

\section{Inclusion criteria}

1. Clinically diagnosed cases of Otitis Media

2. Active purulent discharge at time of examination

\section{Exclusion criteria}

1. Congenitally anomalies involving ear nose oral cavity and pharynxs 
2. Discharge with intact tympanic membrane ( to exclude otitis externa)

3. Patient took antibiotic in last 48 hour.

4. patients less than 1 year or more than 14 year of age,

\section{Sample collection}

The ear discharge from the middle ear was collected by sterile swabs under aseptic conditions with help of aural speculum and sent to the department of Microbiology for bacterial culture. The swab should be replaced in its tube with care not to soil the rim and transport immediately to laboratory. The swab was sub-cultured primarily on Blood Agar, Mac Conkeys agar and Chocolate agar and Thioglycholate broth; and incubated at $37^{\circ} \mathrm{C}$ for an overnight. Subculture from Thioglycholate broth was done if primary inoculation was sterile. The organisms were identified by morphology, cultural characteristics, pigment production and biochemical reaction followed by antibiotic sensitivity test. All the data concerning clinical feature, supporting blood investigation and culture report was analysed and complied in prescribed format. Chi square test was used to calculate $\mathrm{p}$ value with help of SSPS (version 12.0) software (Daniel et al., 2007).

\section{Result and Discussion}

Out of 564 patients males were $49 \%$ and females were $51 \%$. Age of patients was ranging from 1year to 14 years. Higher infection rate was observed in age group 610 year followed by $<1-5$ year. Out of 564 patients, $67 \%$ patients were from OPD, $46.9 \%$ had infection in right ear and $19.8 \%$ had bilateral ear discharge. Only $1.7 \%$ patients had history of fever, $48.3 \%$ children complained of ear ache and $17 \%$ patient had purulent discharge. The most common important symptoms of ear infections are ear discharge, ear pain (78\%), hearing loss $(35 \%)$, vertigo and tinnitus. The clinical findings of patients with Otitis media prevalence mostly in children younger age in our study are similar to findings of previous studies done in India and other developing countries (Rawat et al., 2015).

In our study $53 \%$ culture were sterile in aerobic culture. Reason behind it may be viral origin or other anaerobic bacteria. $89 \%$ growths were mono-microbial while $10.7 \%$ were polymicrobial. Fungus was isolated in $7 \%$ cases in which Aspergillus spp. was most common. Maximum patients were suffered from recurrent upper respiratory infection.

The results of this present work showed that $P$. aeruginosa was the most commonly isolated pathogen $(41.76 \%)$ followed by $S$. aureus (33.34\%).Similar findings have been observed in Ireland, Pakistan and Greece which reported that $P$. aeruginosa and $S$. aureus are the most common organisms isolated from the cases of otitis media (Mukassabi, 2007; Arshad et al., 2004; Bardanis et al., 2003).

This study also provides insights into the susceptibility profile of bacteria isolated from ear infections. Our results have demonstrated that amoxicillin-clavulinic acid, ciprofloxacin, cefepime, teicoplanin, vancomycin, netilmycin, imipenem, amikacin, ofloxacin and gentamicin in general are effective against both Gram positive and negative bacteria isolated from ear infections.

Gram-positive bacteria showed that there was high frequency of sensitivity to cefotaxime, cefoxitin. While ciprofloxacin, Ceftazidim, Gentamicin, cefixeme and ceftriaxone were perfect antimicrobial agents against Gram negative bacteria. 
This susceptibility profile of isolated bacteria provides an evidence for bacterial resistance to many antimicrobial agents by means of multiple drug resistance (MDR), this can be noticed clearly from the susceptibility pattern of $P$. aeruginosa and $S$. aureus and increased frequency of Cefoxitin resistance S. aureus (MRSA) (5.8\%) and this detection of multidrug resistant isolates may further limit therapeutic options. However, there are reports from different parts of the world with high resistance to this antimicrobial agents (Naz et al., 2015; Prakash et al., 2013; Habibu et al., 2015)

Table.1 Distribution of patients according to age

\begin{tabular}{|l|l|l|l|}
\hline Age & Male & Female & Total \\
\hline $1-5$ & $103(54.5 \%)$ & $86(45.5 \%)$ & $189(33.5 \%)$ \\
\hline $6-10$ & $96(42.5 \%)$ & $130(57.5 \%)$ & $226(40 \%)$ \\
\hline $11-14$ & $76(51 \%)$ & $73(49 \%)$ & $149(26.4 \%)$ \\
\hline Total & $275(49 \%)$ & $289(51 \%)$ & 564 \\
\hline
\end{tabular}

Table.2 Types of isolates

\begin{tabular}{|l|l|l|}
\hline Bacterial & 242 & $92.33 \%$ \\
\hline Fungal & 19 & $7.27 \%$ \\
\hline Total & 261 & \\
\hline
\end{tabular}

Table.3 Types of growth

\begin{tabular}{|l|c|c|}
\hline Monomicrobial & 233 & $89.27 \%$ \\
\hline Polymicrobial & 28 & $10.72 \%$ \\
\hline Total & 261 & \\
\hline
\end{tabular}

Table.4 List of isolates

\begin{tabular}{|l|l|l|}
\hline Organism & No. & \%percentage \\
\hline Pseudomonas spp & 109 & $41.76 \%$ \\
\hline Staphylococci aureus & 87 & $33.34 \%$ \\
\hline Klebsiella spp & 19 & $7.27 \%$ \\
\hline Streptococcus pyogenes & 12 & $4.5 \%$ \\
\hline CoNS & 11 & $4.2 \%$ \\
\hline Escherichia coli & 11 & $4.2 \%$ \\
\hline Enterococcus spp & 7 & $2.68 \%$ \\
\hline Citrobacter spp & 5 & $1.9 \%$ \\
\hline Total & 261 & \\
\hline
\end{tabular}


Table.5 Antibiotic susceptibility pattern for gram positive cocci

\begin{tabular}{|l|l|l|l|l|}
\hline Antibiotics & $\begin{array}{l}\text { CoNS } \\
(n=11)\end{array}$ & $\begin{array}{l}\text { Staphylococcus } \\
\text { aureus }(n=87)\end{array}$ & $\begin{array}{l}\text { Streptococcus } \\
\text { pyogenes } \\
(n=12)\end{array}$ & $\begin{array}{l}\text { Enterococci } \\
(n=7)\end{array}$ \\
\hline Vancomycin & $11(100 \%)$ & $87(100 \%)$ & $(100 \%)$ & $(100 \%)$ \\
\hline Erythromycin & $4(37 \%)$ & $45(51.7 \%)$ & $6(50 \%)$ & $3(42.8 \%)$ \\
\hline Clindamycin & $3(27 \%)$ & $41(47 \%)$ & $8(67 \%)$ & $3(42.8 \%)$ \\
\hline Cefotaxime & $4(37 \%)$ & $66(76 \%)$ & $6(50 \%)$ & - \\
\hline Cefepime & $4(37 \%)$ & $65(74.7 \%)$ & $6(50 \%)$ & - \\
\hline Ciprofloxacin & $8(73 \%)$ & $80(92 \%)$ & $12(100 \%)$ & $6(85.7 \%)$ \\
\hline Teicoplanin & $7(64 \%)$ & $81(93 \%)$ & $10(83 \%)$ & $7(100 \%)$ \\
\hline Gentamycin & $10(91 \%)$ & $87(100 \%)$ & $12(100 \%)$ & $7(100 \%)$ \\
\hline $\begin{array}{l}\text { Amoxycillin- } \\
\text { clavulenate }\end{array}$ & $8(73 \%)$ & $82(94 \%)$ & $10(83 \%)$ & $6(85.7 \%)$ \\
\hline Ampicillin & $3(27 \%)$ & $40(46 \%)$ & $4(33 \%)$ & $3(42.8 \%)$ \\
\hline
\end{tabular}

Table.6 Antibiotic susceptibility pattern for gram negative isolates

\begin{tabular}{|l|l|l|l|l|}
\hline & $\begin{array}{l}\text { Psedomonas } \\
n=109\end{array}$ & Citrobacter $n=5$ & Klebsiella $n=19$ & E.coli $n=11$ \\
\hline Ampicillin & - & $3(60 \%)$ & $6(31.5 \%)$ & $6(55 \%)$ \\
\hline Amikacin & $107(98 \%)$ & $2(40 \%)$ & $17(89.47 \%)$ & $10(91 \%)$ \\
\hline Ceftazidime & $69(63.3 \%)$ & $3(60 \%)$ & $13(68.42 \%)$ & $7(64 \%)$ \\
\hline Cefepime & - & $3(60 \%)$ & $7(36.84 \%)$ & $7(64 \%)$ \\
\hline Ciprofloxacin & $103(94 \%)$ & $4(80 \%)$ & $19(100 \%)$ & $10(91 \%)$ \\
\hline $\begin{array}{l}\text { Piperacillin- } \\
\text { tazobactam }\end{array}$ & $99(91 \%)$ & $5(100 \%)$ & $15(78.9 \%)$ & $9(82 \%)$ \\
\hline Imepenem & $109(100 \%)$ & $5(100 \%)$ & $19(100 \%)$ & $11(100 \%)$ \\
\hline Gentamycin & $103(94 \%)$ & $5(100 \%)$ & $19(100 \%)$ & $11(100 \%)$ \\
\hline Netilmycin & $98(90 \%)$ & $4(80 \%)$ & $14(74 \%)$ & $9(82 \%)$ \\
\hline $\begin{array}{l}\text { Amoxycillin- } \\
\text { clavulenate }\end{array}$ & - & $4(80 \%)$ & $14(74 \%)$ & $9(82 \%)$ \\
\hline
\end{tabular}

This difference in the susceptibility profile might be due to frequency of usage of these agents for the treatment of ear infections in different geographic locations. In this area CSOM is more prevalent. The reason behind this may be more people from low socio economic strata, mostly illiterate with poor sanitary habits. They use mainly pond water for cleaning and bathing due to lack of clean water supply.

Patient non-compliance is an important factor responsible for the development of antibiotic resistance. As soon as symptoms subside, many patients stop taking antibiotics before completion of therapy and allow partially resistant microbes to flourish. Such practice should be condemned strongly and patients should be educated to avoid the same for the antibiotics commonly available locally as topical eardrops.

Both Pseudomonas aeruginosa and Staphylococcus aureus are constituents of 
normal flora of the external auditory canal. Pseudomonas to be the most commonly isolated organisms may be that it can grow well in the absence of special nutrition, it proliferates at room temperature and it is highly resistant to antibiotics, making it difficult to treat. Pseudomonas is ubiquitous in our physical environment and has a predilection for the moist areas. It is thought to infect tissues first by adherence to epithelial cells by means of pili or fimbriae. Normal tissues usually resist such attachment, unless there is cellular injury. This phenomenon of opportunistic adherence may represent an important step in the pathogenesis of middle ear infections. Also Pseudomonas has been known to form bacterial biofilms because of which they can resist host defence mechanisms and extremely difficult to eradicate. The frequency of Staphylococcus aureus in the middle ear infections can be attributed to their ubiquitous nature and high carriage of resistant strains in the external auditory canal and upper respiratory tract (Li et al., 2001; Ogbogu et al., 2013).

Result of our study showed high prevalence and resistance rate of Staphylococci and Pseudomonas isolates from otitis media patients to $\beta$ - lactam and other commonly used antimicrobials. Our study suggested that Amoxyclav, ciprofloxacin, PiperacillinTazobactam, Gentamycin, and Netilmycin are best choice in these cases. Therefore an appropriate knowledge of antibacterial susceptibility of microorganism may contribute to rational antibiotic use and the success of treatment for otitis media

\section{References}

Abdel raouf, A., Elmanama, a., Noor, E., Tayyem, A., Salah, A., Allah, N. 2014. The bacterial etiology of otitis media and their antibiogram among children in Gaza Strip, Palestine Egyptian $J$. Ear, Nose, Throat and Allied Sci.,15: 87-91.

Arshad, M., Khan, N.U., Ali, N., Afridi, N.M. 2004. Sensitivity and spectrum of bacterial isolates in infectious otitis externa. J. Coll. Physicians Surg. Pak., 14: 146-149.

Bardanis, J., Batzakakis, D., Mamatas, S. 2003. Types and causes of otorrhea. Auris Nasus Larynx. 30: 253-257.

Basak, B., Chandra, G., Das, M., Dhar, G., Ray, R., Das, A.K. 2014. Demographic profile of CSOM in a rural tertiary care hospital. IOSR J. Pharm., 4: 43-46.

Betty, A., Forbes, Daniel, F., Sahm, Alice, S., Weissfeld, 2007. Bailey and scott's Diagnostic microbiology twelth edition.

Biradar, S.K. 2015. Study of Microbiological Profile and their Antibiogram in Patients with Chronic Suppurative Otitis Media. IJCMAS, 4(9): 981-85.

Farooqui, M.K., Naz, R., Yadav, M. 2016. Sociodemographic profile and type of hearing loss in CSOM from a tertiary care hospital from a rural area. J. Evid. Based Med. Health, 3(2): 56-60.

Habibu, A.U. 2015. Bacteriology of otitis media among patients attending general hospital Bichi, Nigeria The Int. J. Eng. Sci., 4(8): 33-7.

Kumar, S., Sharma, R., Saxena, A., Pandey, A,. Gautam, P., Taneja, V. 2012. Bacterial flora of infected unsafe CSOM. Indian J. Otol., 18: 4-6.

Li, W.C., Chiu, N.C., Hsu, C.H., Lee, K.S., Hwang, H.K., Huang, F.Y. 2001. Pathogens in the middle ear effusion of children with persistent otitis media: implications of drug resistance and complications. J. Microbiol. Immunol. Infect., 34(3): 190-4. 
Mukassabi, K. 2007. Bacteriology of discharging ears. Ir Med J., 100: 379380.

Naz, R., Farooqui, M.K., Girotra, R. 2015. Bacterial profile and antibiotic sensitivity pattern of CSOM patient in mewat region. J. Evid Based Med. Health., 2(61): 9051-54.

Ogbogu, P.I., Eghafona, N.O. and Ogbogu, M.I. 2013. Microbiology of otitis media among children attending tertiary hospital in Benin city, Nigeria, J. Public Health and Epidemiol., 5(7): 280-284.

Park, K. 2002. Text book of Preventive and Social Medicine, XV111 edn; 193.

Prakash, M., Lakshmi, K., Anuradha, S. 2013. Bacteriological profile and their antibiotic susceptibility pattern of case of chronic suppurative otitis media
Asian J. Pharm. Clin. Res., 6(13): 210212.

Rawat, A., Goyal, R. 2015. A Study of Bacterial Profile and Antibiotic Susceptibility Pattern of Chronic Suppurative Otitis Media (CSOM). Internal. J. Microbiol. Appl. Sci., 4(8): 23-27.

Rupa, V., Jacob, V. 1999. Chronic suppurative otitis media; prevalence and practices among rural south Indian Children Int. J. Paedidtric Otolaryngol., 48: 217-21.

Susmita Kumari Sahu, Moningi venkata Narasimham, Indrani. 2007. Microbiological profile of chronic suppurative otitis media and invitro antibiotic sensitivity pattern in a tertiary care hospital. Otolaryngol., 4: 43.

\section{How to cite this article:}

Mohammad Khalid Farooqui, Prakriti Vohra, Ruby Naz, Anil Goel, Akil Hussain, Sameena Khan and A.K. Malik. 2016. Bacterial Aetiology and their Antibiotic Susceptibility Pattern of Otitis Media in Paediatric Age Group. Int.J.Curr.Microbiol.App.Sci. 5(8): 387-393.

doi: http://dx.doi.org/10.20546/ijcmas.2016.508.041 